\title{
Universal screening for cardiovascular disease risk factors in adolescents to identify high-risk families: a population- based cross-sectional study
}

Michael Khoury ${ }^{1}$, Cedric Manlhiot ${ }^{1}$, Don Gibson ${ }^{2}$, Nita Chahal ${ }^{1}$, Karen Stearne ${ }^{2}$, Stafford Dobbin ${ }^{2}$ and Brian W. McCrindle ${ }^{1 *}$

\begin{abstract}
Background: Universal screening of children for dyslipidemia and other cardiovascular risk factors has been recommended. Given the clustering of cardiovascular risk factors within families, one benefit of screening adolescents may be to identify "at-risk" families in which adult members might also be at elevated risk and potentially benefit from medical evaluation.
\end{abstract}

Methods: Cross-sectional study of grade 9 students evaluating adiposity, lipids and blood pressure. Data collected by Heart Niagara Inc. through the Healthy Heart Schools' Program. Parents completed questionnaires, evaluating family history of dyslipidemia, hypertension, diabetes and early cardiovascular disease events in parents and siblings (first-degree relatives), and grandparents (second-degree relatives). Associations between positive risk factor findings in adolescents and presence of a positive family history were assessed in logistic regression models.

Results: $N=4014$ adolescents ages 14-15 years were screened; 3467 (86 \%) provided family medical history. Amongst adolescents, $4.7 \%$ had dyslipidemia, $9.5 \%$ had obesity, and $3.5 \%$ had elevated blood pressure. Central adiposity (waist-to-height ratio $\geq 0.5$ ) in the adolescent was associated with increased odds of diabetes in first(OR:2.0 (1.6-2.6), $p<0.001)$ and second-degree relatives (OR:1.3 (1.1-1.6), $p=0.002)$. Dyslipidemia was associated with increased odds of diabetes (OR:1.6 (1.1-2.3), $p<0.001)$, hypertension (OR:2.2 (1.5-3.2), $p<0.001$ ) and dyslipidemia (OR:2.2 $(1.5-3.2), p<0.001)$ in first degree relatives. Elevated blood pressure did not identify increased odds of a positive family history.

Conclusions: Presence of obesity and/or dyslipidemia in adolescents identified through a universal school-based screening program is associated with risk factor clustering within families. Universal pediatric cardiometabolic screening may be an effective entry into reverse cascade screening.

Keywords: Obesity, Cardiovascular disease, Adolescent, Cardiometabolic risk factors, Cholesterol, Cross-sectional study

\footnotetext{
* Correspondence: brian.mccrindle@sickkids.ca

${ }^{1}$ Labatt Family Heart Centre, Department of Pediatrics, The Hospital for Sick

Children, University of Toronto, 555 University Avenue, Toronto, ON M5G

$1 \times 8$, Canada

Full list of author information is available at the end of the article
}

\section{$\int$ Biomed Central}

(c) 2016 Khoury et al. Open Access This article is distributed under the terms of the Creative Commons Attribution 4.0 International License (http://creativecommons.org/licenses/by/4.0/), which permits unrestricted use, distribution, and reproduction in any medium, provided you give appropriate credit to the original author(s) and the source, provide a link to the Creative Commons license, and indicate if changes were made. The Creative Commons Public Domain Dedication waiver (http://creativecommons.org/publicdomain/zero/1.0/) applies to the data made available in this article, unless otherwise stated. 


\section{Background}

Landmark autopsy studies have shown that, in children who died accidentally, there was an exponential increase in the extent of their atherosclerotic burden as the number of cardiovascular risk factors increased [1-4]. Many of these risk factors are modifiable, such as obesity, dyslipidemia, hypertension, and abnormal glucose metabolism including increased insulin resistance and diabetes. It has been well established that the presence of these risk factors in childhood increases the incidence of cardiometabolic disease in adulthood [5-7]. In addition, cardiovascular risk factors often cluster within members of families, with both genetic and common environmental/behavioral determinants $[8,9]$.

Amongst adults, those between 18 and 44 years old have the lowest health-care utilization [10], creating the potential for delayed identification and management of cardiometabolic risk factors and disease. Children, however, typically receive continuous medical care, and recent integrated guidelines have recommended universal lipid screening of pre-pubertal children [11]. Therefore, screening children for dyslipidemia and other cardiovascular risk factors may serve as an entry point to identifying at-risk family members. We sought to evaluate the association between pediatric cardiometabolic risk factors identified through universal school-based cardiometabolic screening and the presence of elevated cardiometabolic risk factors and cardiovascular disease (CVD) in family members.

\section{Methods}

We conducted a population-based cross-sectional study of grade 9 students (14-15 years old) in the Niagara Region of Ontario, Canada during the 2009-2010 school year. The study was undertaken in co-operation with Heart Niagara Inc. Healthy Heart Schools' Program. This curriculum enrichment program is designed to provide personalized education regarding cardiometabolic risk and healthy lifestyle behaviours, as well as individualized testing, to students in a classroom setting. The program annually targets the entire grade 9 population through their mandatory physical education class (the last school grade where such a mandate exists) in the geographically and administratively defined Niagara Region, Ontario. No students were excluded from participating in the screening. During the 2009-2010 school year, 4104 students participated. All parents of students were provided with questionnaires (described below). Data analysis included all participants who had participated in the screening and had completed the questionnaires. Adolescents presenting with adverse cardiovascular risk profiles were referred back to their primary care provider, where the whole family is encouraged to undergo screening, thus potentially providing a reverse cascade screening tool. The detailed methods of the Healthy Heart Schools'
Program have been previously described [12]. Adolescents provided informed assent and parents/guardians provided written consent to participate in the assessment; the consent included a statement that the participant's deidentified data may be used for research purposes. Formal ethics approval was obtained by Heart Niagara, Inc. from the research ethics committees of both the Niagara Catholic District School Board and the District School Board of Niagara. The Hospital for Sick Children investigators were approved by Heart Niagara, Inc. for secondary use of deidentified data through a negotiated data-sharing agreement between Heart Niagara, Inc. and The Hospital for Sick Children.

\section{Data collection}

Heart Niagara Inc. staff performed all physical measurements during a scheduled assessment day during usual class time. Height and weight measurements were obtained in a standardized manner. Body mass index (BMI) was calculated (weight in kilograms divided by height in meters squared) and age- and sex-specific percentiles and $\mathrm{z}$ scores were determined using the 2006 World Health Organization growth standards [13]. Overweight was defined as a BMI between the 85th and less than the 95th percentile, and obesity was defined as a BMI greater than or equal to the 95th percentile [13]. Waist circumference was measured in a standardized manner, with land marking at the top of the posterior iliac crest with the subject standing. The waist-to-height ratio (WHtR, waist circumference divided by height) was calculated and classified into 3 categories: $<0.5,0.5-<0.6$, and $\geq 0.6$. Previous studies have suggested that a WHtR above 0.5 may be an effective indicator of increased cardiometabolic risk [14-16]. The two remaining categories were based on the methodology of previous studies $[17,18]$.

Finger stick capillary samples were used to obtain nonfasting levels of total cholesterol (TC) and high-density lipoprotein cholesterol (HDL-C). From this, non-high-density lipoprotein cholesterol was calculated (non-HDL-C, TC minus HDL-C).

Blood pressure was evaluated in a standardized manner as previously described [12]. Systolic and diastolic measurements were converted to age-, sex-, and heightspecific percentiles [19]. These values were used to classify the subjects as normotensive (<90th percentile), prehypertensive (90th-<95th percentile), stage 1 hypertensive (95th-<99th percentile), or stage 2 hypertensive ( $\geq 99$ th percentile) [19]. If initial measurements were at or above the 95th percentile, the measurements were repeated. If the second measurement was less than the 95th percentile, that value was used and no further blood pressure measurements were performed. However, if the second measurement was at or above the 95th percentile, 6 automated 
readings were taken at 1-min intervals and the average was calculated.

Students were provided with a questionnaire aimed at reporting whether first degree (siblings and parents) and second-degree relatives (grandparents) had a medical history of dyslipidemia, hypertension, diabetes mellitus, and a history of premature CVD. Premature CVD was defined as any male relative with a heart attack or stroke before 55 years and any female relative before 65 years [12]. The questionnaires were completed at home by the students with help from their parents (for family history questions) and submitted prior to the assessment day.

\section{Data analysis}

Data were analyzed and displayed as means with standard deviations and frequencies, as appropriate. Odds ratios with confidence intervals were used to assess associations between identified cardiometabolic risk factor in adolescents and a positive family history for cardiometabolic risk or early CVD. Only subjects with all completed measurements and a completed questionnaire were included in the analysis. Statistical analyses were performed using SAS statistical software version 9.3 (The SAS Institute, Cary NC).

\section{Results}

Enrollment in the school program for the study period was 4104 adolescents, of which 3467 (85\% of all registered grade 9 students, $50 \%$ male, average age $14.6 \pm$ 0.5 years) adolescents had family history data available. Table 1 shows the descriptive data for the grade 9 participants. Significant differences between male and female students were noted with BMI classification and lipid values. Family history data are shown in Table 2.

Forest plots depicting the odds ratios with confidence intervals for a positive family history of diabetes, dyslipidemia, elevated blood pressure, and/or premature CVD in first and second degree family members (based on parental reporting) for a given identified cardiometabolic risk factor in the adolescents are shown in Fig. 1. Adolescents with increased adiposity (BMI $\geq 95$ th percentile or WHtR $\geq 0.5$ ) had increased odds of having a first- or second-degree family member with diabetes. WHtR showed greater odds ratios than BMI. Adolescents with

Table 1 Characteristics of the study population

\begin{tabular}{|c|c|c|c|c|}
\hline \multirow[t]{2}{*}{ Variable } & Number & Male & Female & $p$ \\
\hline & 3467 & $1718(50 \%)$ & $1749(50 \%)$ & \\
\hline BMI classification (World Health Organization) & 3382 & & & 0.002 \\
\hline Underweight (<5th percentile) & & $36(2 \%)$ & $32(2 \%)$ & \\
\hline Normal weight ( $\geq 5$ th $-<85$ th percentile) & & $1042(62 \%)$ & $1157(68 \%)$ & \\
\hline Overweight ( $\geq 85$ th $-<95$ th percentile) & & $251(15 \%)$ & $239(14 \%)$ & \\
\hline Obese ( $\geq 95$ th percentile) & & 349 (21\%) & $276(16 \%)$ & \\
\hline Waist-to-height ratio & 3382 & & & 0.24 \\
\hline$<0.5$ & & $1324(79 \%)$ & $1379(81 \%)$ & \\
\hline $0.5-<0.6$ & & $281(17 \%)$ & $266(16 \%)$ & \\
\hline$\geq 0.6$ & & $73(4 \%)$ & $59(3 \%)$ & \\
\hline Elevated blood pressure (maximum systolic/diastolic blood pressure) & 3359 & & & \\
\hline Normal (<90th percentile) & & $1526(91 \%)$ & $1544(91 \%)$ & 0.46 \\
\hline Pre-hypertension (90-<95th percentile) & & $76(5 \%)$ & $91(5 \%)$ & \\
\hline Stage 1 hypertension (95th-<99th percentile) & & $52(3 \%)$ & $44(3 \%)$ & \\
\hline Stage 2 hypertension ( $\geq 99$ th percentile) & & $15(1 \%)$ & $11(1 \%)$ & \\
\hline Total cholesterol classification & 3061 & & & $<0.001$ \\
\hline Normal (<4.4 mmol/L) & & $1282(84 \%)$ & $1122(73 \%)$ & \\
\hline Borderline high $(4.4-<5.2 \mathrm{mmol} / \mathrm{L})$ & & $191(13 \%)$ & $323(21 \%)$ & \\
\hline High ( $\geq 5.2 \mathrm{mmol} / \mathrm{L})$ & & $50(3 \%)$ & $93(6 \%)$ & \\
\hline Low high-density lipoprotein (HDL-C) (<1.03 mmol/L) & 3005 & $572(38 \%)$ & $279(18 \%)$ & $<0.001$ \\
\hline Non-high density lipoprotein (non-HDL-C) classification & 3061 & & & 0.001 \\
\hline Normal & & $1224(80 \%)$ & $1149(75 \%)$ & \\
\hline Borderline high ( $\geq 3.10$ to $<3.75 \mathrm{mmol} / \mathrm{L})$ & & $196(13 \%)$ & $268(17 \%)$ & \\
\hline High ( $\geq 3.75 \mathrm{mmol} / \mathrm{L})$ & & $103(7 \%)$ & $121(8 \%)$ & \\
\hline
\end{tabular}

$\mathrm{P}$ values correspond to differences between males and females regarding classification distribution or prevalence of abnormalities 
Table 2 Family history

\begin{tabular}{lll}
\hline & Number & Positive history (\%) \\
\hline Diabetes mellitus-1st degree & 3296 & $291(9 \%)$ \\
Diabetes mellitus-2nd degree & 3311 & $1457(44 \%)$ \\
Hypertension-1st degree & 3229 & $702(22 \%)$ \\
Hypertension-2nd degree & 3240 & $1956(60 \%)$ \\
Hyperlipidemia-1st degree & 3193 & $618(19 \%)$ \\
Hyperlipidemia-2nd degree & 3206 & $1670(52 \%)$ \\
Early atherosclerotic event & 3467 & $1127(34 \%)$ \\
\hline
\end{tabular}

an elevated TC had increased odds of having a firstdegree family member with diabetes, dyslipidemia or hypertension. Adolescents with an elevated non-HDL-C had increased odds of having a first-degree family member with diabetes, dyslipidemia, or hypertension, and a second-degree family member with diabetes. Adolescents with elevated blood pressure did not have increased odds of having a family member with a positive family history. None of the measured cardiometabolic risk factors in adolescents were significantly associated with increased odds of having a positive family history of premature CVD.

\section{Discussion}

The findings of our study indicate that cardiometabolic risk factors identified through universal school-based screening of adolescents is associated with the presence of risk factors in family members. The presence of dyslipidemia was associated with a positive family history of diabetes, dyslipidemia, and hypertension while the presence of increased adiposity was associated with a positive family history of diabetes. Adolescents with increased blood pressure measurements did not have increased odds of having family members with increased cardiometabolic risk factors. It should be noted that the elevated blood pressure measurements identified in a universal screening setting are not indicative of a diagnosis of hypertension. This may partially explain why no associations were seen in these subjects. Future studies are required to evaluate this further. No cardiometabolic risk factors in adolescents were associated with increased odds of an early CVD event in a family member. However, obesity, elevated WHtR, and dyslipidemia showed trends towards increased odds.

A number of studies have assessed the association between pediatric cardiometabolic risk factors and the presence of cardiovascular risk factors and disease in

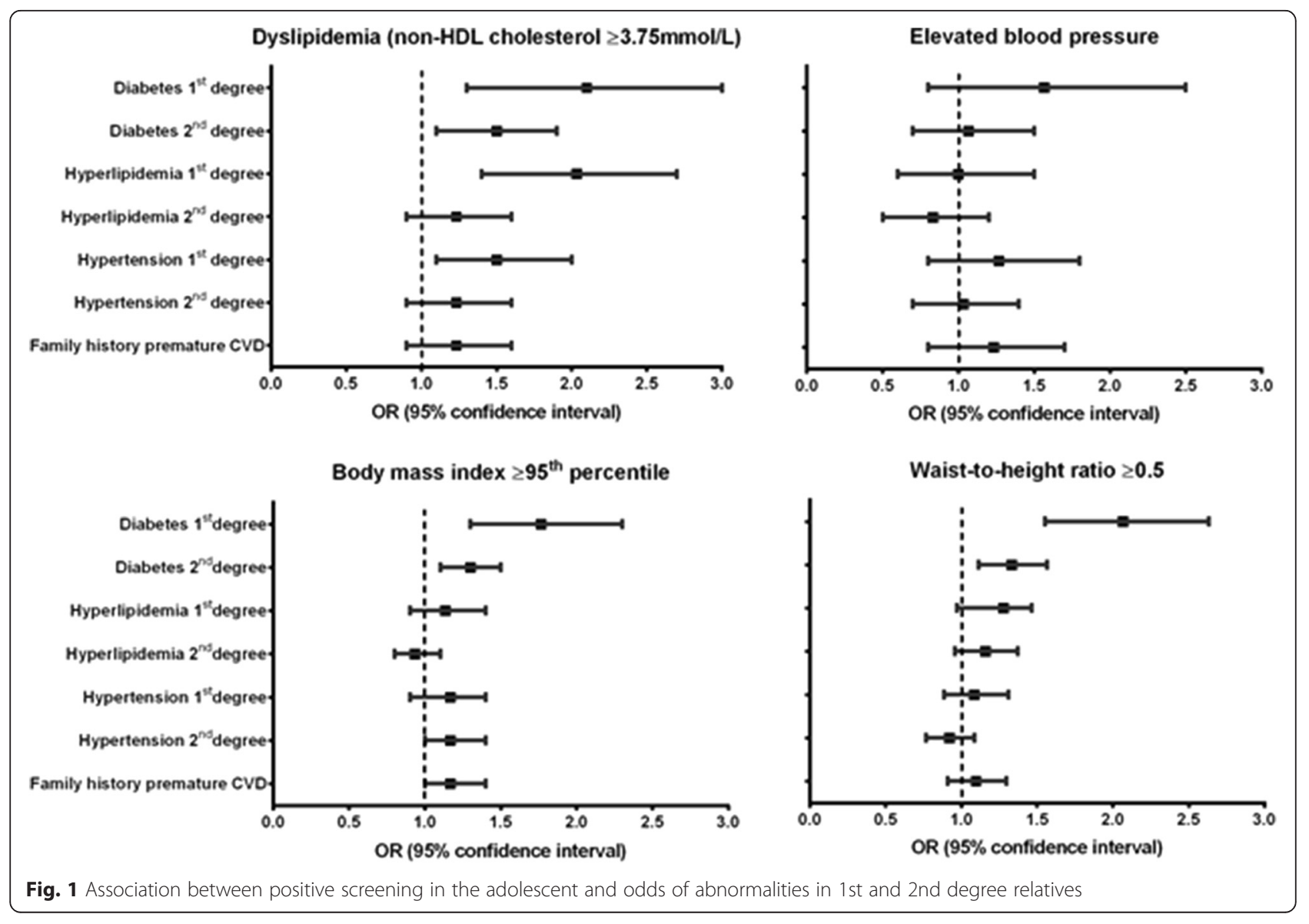


family members. Morrison et al.[20] recently evaluated the utility of risk factor screening in 5-19 year-old school children for predicting families at high risk for parental CVD, type 2 diabetes and high blood pressure 26 years later. They found the risk for CVD was greater if children had high TC (relative risk (RR) 1.30) or high low-density lipoprotein cholesterol (LDL-C) (RR 1.26) on screening. Risk for paternal type 2 diabetes was higher in families with pediatric high BMI (RR 1.53). Risk for parental high blood pressure was higher in children who were overweight (BMI $\geq 85$ th percentile, $R R$ 1.23), had an elevated LDL-C (RR 1.15), or elevated blood pressure (RR 1.22). In addition, significant child-parent correlations for TC, HDL-C, LDL-C, and glucose were observed. This study concluded that identifying parents, initiated through screening of their children (reverse cascade screening), could possibly identify a cohort of young adults where interventions could be initiated to prevent later CVD, diabetes and hypertension. Our present study showed that parents of adolescents with cardiometabolic risk factors already have increased odds of silent (dyslipidemia and hypertension) and overt (diabetes) cardiometabolic disease. Therefore, not only are family members of children with cardiometabolic risk factors at increased risk of developing cardiometabolic disease in the future, they appear to be at increased risk of having cardiometabolic disease at the time of the school-based screening.

Reis et al.[21] found that parents of children who were obese or had an elevated waist circumference had about 6 times increased odds of having obesity or an increased waist circumference themselves, while children who had hypertension had 15 times increased odds of having a parent with hypertension. These are stronger associations than those observed in our study, possibly due to the small sample size (children and parents from 94 families) and a heterogeneous, high-risk population (52\% of subjects were overweight or obese, $33 \%$ had an elevated waist circumference and $69 \%$ were black). A German study [22] found that children with an elevated waist circumference had 2.55 times increased odds of having a parent with increased waist circumference, while children with elevated blood pressure did not have increased odds of having a parent with hypertension. A child with a raised non-HDL-C had 2.90 times increased odds of having a parent with an increased non-HDL-C. These results are generally similar to the findings in our study, with slightly greater odds ratio values. However, the results of this study may not be generalizable as it used a young (mean age 6.8 years), solely German population with a low incidence of obesity (4.5-4.9\% of children). In addition, similar to Reis et al.[21], this study focused on child-parent correlations for a given cardiometabolic risk factor, whereas our study assessed the odds of a positive family history of dyslipidemia, hypertension, diabetes, and premature CVD for each identified pediatric risk factor.

Muratova et al.[23] performed nonfasting lipid screening of 709 fifth grade children, with confirmation testing for those who screened positive. Of children with confirmed dyslipidemia, $66 \%$ of their parents had confirmed dyslipidemia. The study may not be universally applicable as it took place in a high-risk area, with low education, low socioeconomic status, and low levels of cholesterol screening among adults. In addition, only $36 \%$ of the children who screened positive had confirmatory testing due to logistical issues. Gidding et al.[24] and Polonsky et al.[25] have both shown that children with abnormal lipid levels have an increased incidence of having one or both parents with a lipid disorder. Two studies have shown an increased incidence of premature CVD in grandfathers of dyslipidemic children [26, 27].

Overall, our study shows similar trends to those noted in the literature outlined above, namely that children may be an effective proband for identifying parents and families at risk. However, there are some novel features and findings of the current study. First, our study was performed within an established universal screening program performed in a school-based setting with a large number of subjects. Second, our study assessed a selfreported history of established hypertension, dyslipidemia, and diabetes in family members, showing increased odds of manifest cardiometabolic disease in family members of children with cardiometabolic risk factors. Third, this study showed that children who screened positive for dyslipidemia had increased odds of having parents or siblings with dyslipidemia, hypertension, and diabetes. Identifying a raised risk profile of established cardiometabolic disease in parents and siblings of dyslipidemic children that is this broad is a significant finding. In addition, these results indicate that universal pediatric lipid screening may also identify family members with previously undiagnosed cardiometabolic disease, thus making it a potentially effective entry into reverse cascade screening. Further studies are needed to confirm this.

Recent guidelines [11] have recommended universal lipid screening of all pre-pubertal children between the ages of 9-11, with the aim of early identification of both dyslipidemia of obesity and genetic disorders of dyslipidemia, such as familial hypercholesterolemia (FH). This recommendation has been met with controversy and debate [28-30], with some concerns raised as to whether the available evidence justified the recommendation. The present study has shown a potential added benefit of universal lipid screening that may not have been considered previously: universal school-based lipid screening, when coupled with family history assessment, may identify risk factors clustering within families. Heterozygous FH is relatively common, with a prevalence of at least 
1:500 in North America. If left untreated, approximately $25 \%$ of females and $50 \%$ of males will experience a CVD event by the age of 50 [31]. Lipid screening in children can potentially identify previously undetected $\mathrm{FH}$, possibly creating the conditions for an effective and efficient public health initiative. As children typically have parents in an age cohort that typically does not partake in regular health-care visits, identifying children at risk may allow for early identification and intervention for both the child and the parents.

There are a number of limitations that should be considered when interpreting the results of this study. Given the cross-sectional design, only associations, but not causality, can be inferred. As data were collected within a universal screening program, family history data was obtained from questionnaires rather than direct detection of cardiovascular risk factors through measurement of family members. This does not allow for the detection of previously undiagnosed cardiometabolic risk factors or disease in family members. Given that previous studies have shown a large proportion of identified disease in family members to be previously undiagnosed $[23,24]$, the results of our study may be interpreted as conservative estimates of the true increased risk in family members. However, given that the family history information was obtained from a questionnaire, its accuracy cannot be ensured. In future studies it will be important to perform direct measurements on family members in order to detect previously undiagnosed cardiometabolic risk factors and disease. This will allow a stronger evaluation of the utility of universal pediatric screening as a reverse cascade-screening tool in the detection of cardiometabolic risk factors and disease in family members. Further, the ages of the parents, siblings, and grandparents were unfortunately not available. Ethnicity and pubertal staging data were unavailable. Morrison et al. had previously shown that pubertal status was not a significant explanatory variable for parental outcomes [20]. Finally, the Heart Niagara Inc. screening program currently screens grade 9 students. This is not in keeping with the current expert panel guidelines [11], which suggest the first screening in the pre-pubertal grade 5 population. Future school-based screening studies are needed in this younger population to help further validate the guidelines.

\section{Conclusions}

Adolescents who have cardiometabolic risk factors, identified through universal screening, have increased odds of having family members with diagnosed cardiometabolic risk factors and disease. This indicates that school-based cardiometabolic screening, along with family history assessment, may identify risk factor clustering within families. Future studies are needed to assess the effectiveness of screening pre-pubertal children to help validate recent expert panel guidelines. In addition, further studies are required to establish school-based cardiometabolic screening as an effective reverse cascade-screening tool to detect previously undiagnosed cardiometabolic disease in family members.

\section{Abbreviations}

BMl: body mass index; CVD: cardiovascular disease; HDL-C: high-density lipoprotein cholesterol; LDL-C: low-density lipoprotein cholesterol; non-HDLC: non-high-density lipoprotein cholesterol; OR: odds ratio; RR: relative risk;

TC: total cholesterol; WHtR: waist-to-height ratio.

\section{Competing interests}

The authors declare that they have no competing interests.

\section{Authors' contributions}

MK conceived the study, interpreted the data and drafted the manuscript. CM analyzed the data, interpreted the data and drafted the manuscript. DG conceived the study, collected the data and interpreted the data. NC and KS conceived the study, collected the data and interpreted the data. SD conceived the study, interpreted the data. BWM conceived the study, analyzed the data and interpreted the data. All authors read and approved the final manuscript.

\section{Acknowledgements}

This work was supported by the CIBC World Markets Children's Miracle Foundation Chair in Child Health Research and the Canadian Institute of Health Research Team Grant in Childhood Obesity.

\section{Author details}

${ }^{1}$ Labatt Family Heart Centre, Department of Pediatrics, The Hospital for Sick Children, University of Toronto, 555 University Avenue, Toronto, ON M5G 1X8, Canada. ${ }^{2}$ Heart Niagara Inc., Niagara Falls, ON, Canada.

Received: 19 April 2014 Accepted: 12 January 2016

Published online: 21 January 2016

\section{References}

1. Newman 3rd WP, Freedman DS, Voors AW, Gard PD, Srinivasan SR, Cresanta JL, et al. Relation of serum lipoprotein levels and systolic blood pressure to early atherosclerosis. The Bogalusa heart study. N Engl J Med. 1986;314:138-44.

2. Berenson GS, Srinivasan SR, Bao W, Newman 3rd WP, Tracy RE, Wattigney WA. Association between multiple cardiovascular risk factors and atherosclerosis in children and young adults. The Bogalusa heart study. N Engl J Med. 1998:338:1650-6.

3. McMahan CA, McGill HC, Gidding SS, Malcom GT, Newman WP, Tracy RE, et al. PDAY risk score predicts advanced coronary artery atherosclerosis in middle-aged persons as well as youth. Atherosclerosis. 2007;190:370-7.

4. McMahan CA, Gidding SS, Malcom GT, Tracy RE, Strong JP, McGill Jr HC. Pathobiological determinants of atherosclerosis in youth risk scores are associated with early and advanced atherosclerosis. Pediatrics. 2006:118:1447-55.

5. Morrison JA, Friedman LA, Gray-McGuire C. Metabolic syndrome in childhood predicts adult cardiovascular disease 25 years later: the Princeton lipid research clinics follow-up study. Pediatrics. 2007;120:340-5.

6. Baker JL, Olsen LW, Sorensen TI. Childhood body-mass index and the risk of coronary heart disease in adulthood. N Engl J Med. 2007;357:2329-37.

7. Freedman DS, Khan LK, Serdula MK, Dietz WH, Srinivasan SR, Berenson GS. The relation of childhood BMI to adult adiposity: the Bogalusa heart study. Pediatrics. 2005:115:22-7.

8. Chen W, Srinivasan SR, Elkasabany A, Berenson GS. The association of cardiovascular risk factor clustering related to insulin resistance syndrome (syndrome $X$ ) between young parents and their offspring: the Bogalusa heart study. Atherosclerosis. 1999;145:197-205.

9. Chen W, Srinivasan SR, Bao W, Berenson GS. The magnitude of familial associations of cardiovascular risk factor variables between parents and offspring are influenced by age: the Bogalusa heart study. Ann Epidemiol. $2001 ; 11: 522-8$. 
10. Bernstein ABHE, Moss AJ, Allen KF, Siller AB, Tiggle RB. Health care in America: trends in utilization. National Center for Health Statistics: Hyattsville, Maryland; 2003.

11. Expert panel on integrated quidelines for cardiovascular health and risk reduction in children and adolescents. Summary report. Pediatrics 2011; 128(Suppl 5):S213-256.

12. McCrindle BW, Manlhiot C, Millar K, Gibson D, Stearne K, Kilty H, et al. Population trends toward increasing cardiovascular risk factors in Canadian adolescents. J Pediatr. 2010;157:837-43.

13. de Onis M, Onyango AW, Borghi E, Siyam A, Nishida C, Siekmann J, Development of a WHO growth reference for school-aged children and adolescents. Bull World Health Organ. 2007;85:660-7.

14. McCarthy HD, Ashwell M. A study of central fatness using waist-to-height ratios in UK children and adolescents over two decades supports the simple message-'keep your waist circumference to less than half your height'. Int J Obes. 2006;30:988-92.

15. Ashwell M, Hsieh SD. Six reasons why the waist-to-height ratio is a rapid and effective global indicator for health risks of obesity and how its use could simplify the international public health message on obesity. Int J Food Sci Nutr. 2005:56:303-7.

16. Hsieh SD, Muto T. The superiority of waist-to-height ratio as an anthropometric index to evaluate clustering of coronary risk factors among non-obese men and women. Prev Med. 2005;40:216-20.

17. Khoury M, Manlhiot C, McCrindle BW. Role of the waist/height ratio in the cardiometabolic risk assessment of children classified by body mass index. J Am Coll Cardiol. 2013:62:742-51.

18. Khoury M, Manlhiot C, Dobbin S, Gibson D, Chahal N, Wong H, et al. Role of waist measures in characterizing the lipid and blood pressure assessment of adolescents classified by body mass index. Arch Pediatr Adolesc Med. 2012;166:719-24

19. National High Blood Pressure Education Program Working Group on High Blood Pressure in Children and Adolescents. The fourth report on the diagnosis, evaluation, and treatment of high blood pressure in children and adolescents. Pediatrics 2004; $114(2$ Suppl):555-576.

20. Morrison JA, Glueck CJ, Wang P. The child as proband for future parenta cardiometabolic disease: the 26-year prospective Princeton lipid research clinics follow-up study. J Pediatr. 2012:160:590-7. e593.

21. Reis EC, Kip KE, Marroquin OC, Kiesau M, Hipps Jr L, Peters RE, et al. Screening children to identify families at increased risk for cardiovascular disease. Pediatrics. 2006;118:e1789-97.

22. Schwandt P, Bischoff-Ferrari HA, Staehelin HB, Haas GM. Cardiovascular risk screening in school children predicts risk in parents. Atherosclerosis. 2009: 205:626-31.

23. Muratova VN, Islam SS, Demerath EW, Minor VE, Neal WA. Cholesterol screening among children and their parents. Prev Med. 2001;33:1-6.

24. Gidding SS, Whiteside P, Weaver S, Bookstein L, Rosenbaum D, Christoffel K. The child as proband. High prevalence of unrecognized and untreated hyperlipidemia in parents of hyperlipidemic children. Clin Pediatr. 1989;28:462-5

25. Polonsky SM, Simbartl LA, Sprecher DL. Triglyceride and high-density lipoprotein cholesterol: predicting disorders in parents from their children. Pediatrics. 1994;94:824-31.

26. Moll PP, Sing CF, Weidman WH, Gordon H, Ellefson RD, Hodgson PA, et al. Total cholesterol and lipoproteins in school children: prediction of coronary heart disease in adult relatives. Circulation. 1983;67:127-34.

27. Schrott HG, Clarke WR, Wiebe DA, Connor WE, Lauer RM. Increased coronary mortality in relatives of hypercholesterolemic school children: the Muscatine study. Circulation. 1979;59:320-6.

28. Newman TB, Pletcher MJ, Hulley SB. Overly aggressive new guidelines for lipid screening in children: evidence of a broken process. Pediatrics. 2012; 130:349-52.

29. McCrindle BW, Kwiterovich PO, McBride PE, Daniels SR, Kavey RE. Guidelines for lipid screening in children and adolescents: bringing evidence to the debate. Pediatrics. 2012;130:353-6.

30. Gillman MW, Daniels SR. Is universal pediatric lipid screening justified? JAMA. 2012;307:259-60.

31. Kwiterovich Jr PO. Recognition and management of dyslipidemia in children and adolescents. J Clin Endocrinol Metab. 2008:93:4200-9.

\section{Submit your next manuscript to BioMed Central and we will help you at every step:}

- We accept pre-submission inquiries

- Our selector tool helps you to find the most relevant journal

- We provide round the clock customer support

- Convenient online submission

- Thorough peer review

- Inclusion in PubMed and all major indexing services

- Maximum visibility for your research

Submit your manuscript at www.biomedcentral.com/submit
C Biomed Central 